\title{
Src Family Kinases and Syk Are Required for Neutrophil Extracellular Trap Formation in Response to $\beta$-Glucan Particles
}

\author{
Sara Nanì ${ }^{a}$ Laura Fumagalli ${ }^{a} \quad$ Uma Sinhab $^{\mathrm{b}}$ Lynn Kamen $^{\mathrm{b}}$ Patrizia Scapini $^{\mathrm{a}}$ \\ Giorgio Berton ${ }^{\mathrm{a}}$ \\ a Section of General Pathology, Department of Pathology and Diagnostics, University of Verona, Verona, Italy; \\ bPortola Pharmaceuticals Inc., San Francisco, Calif., USA
}

\section{Key Words}

Neutrophil extracellular traps $\cdot$ Src family kinases $\cdot$ Syk .

Signal transduction $\cdot$ Reactive oxygen species

\begin{abstract}
We report that particles of $\beta$-glucan, one of the surface components of yeasts, are powerful inducers of neutrophil extracellular trap (NET) formation in human neutrophils. $\beta$-Glucan triggered a prolonged phosphorylation of Src family kinases and Syk that were suppressed by the Src family inhibitor 4-amino-5-(4-chlorophenyl)-7-(t-butyl)pyrazolo[3, 4-d] pyrimidine (PP2) and a novel Syk inhibitor, PRT-060318, respectively. PP2 and PRT-060318 also inhibited $\beta$-glucan-induced NET formation and reactive oxygen species (ROS) generation, suggesting that both responses are triggered by a Src/ Syk-regulated signaling pathway. Given that the NADPH oxidase inhibitor diphenyleneiodonium chloride (DPI) markedly inhibited NET formation, our findings suggest that ROS are required for the full-blown formation of NETs in response to $\beta$-glucan particles. Contrary to $\beta$-glucan, ROS generation triggered by phorbol myristate acetate (PMA) was unaffected by PP2 and PRT-060318, but these compounds, as well as DPI, suppressed Src/Syk phosphorylation triggered by PMA. Whereas PP2 had no effect on PMA-induced NET formation, PRT-060318 had a significant, albeit partial, inhibitory effect, thus suggesting that ROS induce NET formation in part via
\end{abstract}

(c) 2014 S. Karger AG, Basel

1662-811X/14/0071-0059\$39.50/0 activation of Syk. These findings were substantiated by the evidence that neutrophils from mice with the conditional deletion of Syk were defective in formation of NETs in response to $\beta$-glucan.

(c) 2014 S. Karger AG, Basel

\section{Introduction}

Neutrophil extracellular traps (NETs) are externalized web-like structures composed of decondensed nuclear chromatin associated with histones and granule antimicrobial proteins. Since their discovery in 2004 [1], NETs have received increasing attention as a mechanism by which granulocytes exert their microbicidal activity. A wide variety of pathogens including, bacteria, fungi and protozoan parasites have been reported to trigger NET formation and be killed by these structures released by dying neutrophils [for reviews, see 2, 3].

Consistent with the notion that innate host defenses behave like a double-edged sword, more recently NETs have been implicated in the pathogenesis of autoimmune and inflammatory diseases including vasculitis [4] systemic lupus erythematosus [5], gout [6], infection- and transfusion-related acute lung injury $[7,8]$ and deep venous thrombosis [9; for reviews, see 2, 3]. These last findings highlight a new strategy to control inflammation- 
based pathologies based on inhibition of NET formation. Intriguingly, in cystic fibrosis patients aerosolized DNase has been used for 20 years to break up sticky secretion containing NETs [10].

Targeting NET formation as a way to inhibit inflammation is made difficult by the limited amount of information available on signaling pathways regulating this neutrophil response. To date, the strongest progress made in characterizing mechanisms of regulation of NET formation is represented by identification of reactive oxygen species (ROS) as essential elements in triggering the complex machinery implicated in nuclear and granule membrane collapse, chromatin decondensation and extrusion of DNA/granule protein-containing fibers $[11,12]$.

To start to elucidate signaling pathways implicated in NET formation, we addressed this issue using a specific agonist of neutrophil activation, i.e. $\beta$-glucan, a component of the yeast surface buried under a layer of mannan, but exposed in budding yeasts and hyphae $[13,14]$. Notably, NETs trap and kill Candida albicans yeast and hyphal forms [15], and more recently particulate $\beta$-glucan has been reported to induce NET formation in primed neutrophils adherent to fibronectin [16]. Innate immunity cells express diverse surface receptors recognizing $\beta$-glucan; these include the C-type lectin Dectin-1 [17], the scavenger receptors SCARF1 and CD36 [18], and the $\alpha \mathrm{M} \beta_{2}$ integrin (complement receptor type 3 or CD11b/ CD18) [19] [for reviews, see 13, 14]. While these receptors may play different roles in recognition of $\beta$-glucan by murine or human neutrophils, Dectin-1, $\alpha \mathrm{M} \beta_{2}$, and, as reported in a very recent study, CD36 itself [20], share a common signal transduction pathway implicating $\mathrm{Src}$ family kinases, ITAM-containing adaptor proteins and Syk $[13,14,21-23]$. Here, we report that $\beta$-glucan particles are potent inducers of NET formation in human neutrophils and their action requires particle internalization. Comparing the effect of Src family kinase inhibitors and the inhibitor of the NADPH oxidase diphenyleneiodonium (DPI) on NET formation, ROS generation and the activation of Src kinases and Syk in response to $\beta$-glucan and phorbol myristate acetate (PMA), we present evidence that, within the signal transduction pathway triggered by $\beta$-glucan particles, Src kinases and Syk are upstream of ROS, but these are indispensable for the eventual formation of NETs. In contrast, even though formation of ROS in response to PMA results in activation of Src kinases and Syk, this stimulus triggers directly NET formation via ROS. The use of a new generation Syk inhibitor, PRT-060318, allowed us to conclude that NET formation induced by ROS is in part due to their capabil- ity to activate Syk. Additionally, we show that in murine neutrophils Syk deficiency hampers both NET and ROS formation in response to $\beta$-glucan.

Although both in vitro and in vivo studies are required to establish whether the Src/Syk signaling pathway implicated in $\beta$-glucan-induced NET formation plays a role in NET formation in the context of autoimmune or inflammatory disease (see above), our findings highlight a possible target to control NET formation in human pathologies. In the context of fungal infection, it is important to note that an uncontrolled inflammatory response characterizing the so-called fungus-related immune reconstitution inflammatory syndrome in severe infections may contribute to disease severity [24]. Thus, our findings may suggest a new strategy to control overstimulation of neutrophils in fungal infections.

\section{Materials and Methods}

\section{Reagents and Antibodies}

Ficoll Paque Plus and dextran-500 were from Amersham Biosciences (Amersham Co., Arlington Heights, Ill., USA). RPMI 1640 (RPMI) medium was from Lonza (Basel, Switzerland). Hank's balanced salt solution (HBSS) and Alexa Fluor ${ }^{\circledR} 488$ Goat Anti-Mouse IgG were from Life Technologies Corporation (Paisley, UK). $\beta$-Glucan from Saccharomyces cerevisiae (product number G5011), PMA, DAPI, horseradish peroxidase, isoluminol, piceatannol, phenylarsine oxide, diisopropyl-fluorophosphate and human fibrinogen were from Sigma-Aldrich (St. Louis, Mo., USA). Protease inhibitors were from Roche Molecular Biochemicals (Mannheim, Germany). 4-amino-5-(4-chlorophenyl)-7-(t-butyl) pyrazolo [3, 4-d] pyrimidine (PP2) and DPI were from Calbiochem (Darmstadt, Germany). Anti-neutrophil elastase and anti-myeloperoxidase antibodies (Abs) were from Abcam (Cambridge, Mass., USA). NorthernLights Anti-rabbit IgG-N1637 was from R\&D System (Minneapolis, Minn., USA). Lyn (phospho Tyr396) and Vav (phospho Tyr174) Abs were from GeneTex (Irvine, Calif., USA). Syk (phospho Tyr525/526) Ab was from Cell Signaling (Beverly, Mass., USA). Anti-protein Abs directed against Lyn (H-6) and Syk (N-19) were from Santa Cruz Biotechnology (Santa Cruz, Calif., USA). PRT-060318 was a kind gift from Portola Pharmaceuticals Inc., San Francisco, Calif., USA.

To prepare the $\beta$-glucan suspension, the dry powder was suspended at $5 \mathrm{mg} / \mathrm{ml}$ in PBS, sonicated to disrupt the biggest aggregate and then passed through $70-\mu \mathrm{m}$ cell strainer (BD Falcon, Franklin Lakes, N.J., USA) to get rid of a few big aggregates.

\section{Neutrophil Isolation}

Human PMNs were prepared from buffy coats of healthy volunteers by centrifugation through Ficoll Paque Plus (Amersham). Patients provided their informed consent before samples were taken. Contaminating erythrocytes were removed by Dextran 500 (Amersham) sedimentation followed by hypotonic lysis. After isolation, cells were suspended at $10 \times 10^{6} / \mathrm{ml}$ in HBSS supplemented with $0.5 \mathrm{mM} \mathrm{CaCl}_{2}$ and $5 \mathrm{mM} \mathrm{D}$-glucose (HGCa) 
for ROS production or in RPMI for NET formation. Neutrophils were either left untreated or incubated at $37^{\circ} \mathrm{C}$ with $10 \mu \mathrm{M}$ PP2 or $20 \mu \mathrm{M}$ DPI for $10 \mathrm{~min}, 1.0 \mu \mathrm{M}$ PRT- 060318 for $15 \mathrm{~min}$ or $50 \mu \mathrm{M}$ piceatannol for $30 \mathrm{~min}$, before stimulation. Syk-deficient neutrophils were isolated from the bone marrow of $S y k^{f / f} V a v 1 c r e^{T g}$ mice, carrying the Syk deletion in the hematopoietic system, as previously described [25]. Neutrophils isolated from the bone marrow of $S y k^{f / f}$ and/or $V a v 1 c r e^{T g}$ mice were used as controls. As the latter mice showed similar results, for clarity, the data from these two groups were pooled and defined as the control group. Mouse neutrophils were isolated as described previously [26]. Briefly, bone marrow cells were flushed from the bones using HBSS without $\mathrm{Ca}^{2+}$ and $\mathrm{Mg}^{2+}$, and containing $0.1 \%$ BSA. Cells were centrifuged and, after hypotonic lysis of erythrocytes, resuspended in $3 \mathrm{ml}$ of $\mathrm{Ca}^{2+} / \mathrm{Mg}^{2+}$-free HBSS supplemented with $0.1 \%$ BSA. Bone marrow cells were then loaded on top of a Percoll discontinuous density gradient and, after centrifugation at $1,600 \mathrm{~g}$ for $30 \mathrm{~min}$ at room temperature, cells at the interface between 81 and $62 \%$ were harvested and diluted in $\mathrm{Ca}^{2+} / \mathrm{Mg}^{2+}$ free HBSS supplemented with $0.1 \%$ BSA. After an additional wash, neutrophils were resuspended in HGCa. Syk expression in control and $\mathrm{syk}^{-/-}$murine neutrophils was examined by Western blotting (see below) using anti-Syk Abs from Santa Cruz Biotechnology.

\section{NET Formation}

$5 \times 10^{4}$ neutrophils, suspended in RPMI, were stimulated in a black 96-well plate that had been previously precoated with $250 \mu \mathrm{g} /$ $\mathrm{ml}$ human fibrinogen. Cells were incubated for $3 \mathrm{~h}$ at $37^{\circ} \mathrm{C}$ in a $5 \%$ $\mathrm{CO}_{2}$ incubator without any stimulus or in the presence of $20 \mathrm{ng} /$ ml PMA or different doses of $\beta$-glucan (see text). At the end of the incubation, NET-DNA was stained by adding SYTOX Green (Invitrogen, Paisley, UK) at a $5 \mu \mathrm{M}$ final concentration. The plates were read in a fluorescence microplate reader (Victor 3, PerkinElmer; Waltham, Mass., USA) with a filter setting of 485/535 nm (excitation/emission). Coating of the wells with fibrinogen was performed because we noticed that on plain plastic the SYTOX green signal detected in unstimulated cells displayed quite a high variability with different cell preparations probably due to neutrophil spreading on plastic [see 26].

\section{Immunofluorescence and Confocal Microscopy}

$2 \times 10^{5}$ neutrophils were seeded on glass coverslips treated with $0.01 \%$ poly-lysine (Sigma). After treatment with different inhibitors and incubation with $\beta$-glucan or PMA as described above, cells were fixed with $4 \%$ PFA for $45 \mathrm{~min}$ at room temperature, quenched with $50 \mathrm{mM} \mathrm{NH}_{4} \mathrm{Cl}$ for $1 \mathrm{~min}$, permeabilized with $0.2 \%$ Triton X-100 for 5 min and blocked with 1\% BSA for $1 \mathrm{~h}$. For protein immunostaining, the cells were incubated for $30 \mathrm{~min}$ with a mouse monoclonal $\mathrm{Ab}$ against myeloperoxidase (Abcam, Cambridge, UK; ab25989) and rabbit polyclonal Abs against neutrophil elastase (Abcam; ab21595) both at a $5 \mu \mathrm{g} / \mathrm{ml}$ concentration. Primary Abs were detected with Alexa Fluor 488-labeled (excitation $495 \mathrm{~nm} /$ emission $519 \mathrm{~nm}$ ) or NorthernLights NL637 (excitation $637 \mathrm{~nm} / \mathrm{emission} 658 \mathrm{~nm}$ ) secondary Abs after incubation for 45 min. DNA was stained with DAPI (Invitrogen) for $10 \mathrm{~min}$. The coverslips were mounted with fluorescent mounting medium (Dako; Glostrum, Denmark), and the cells were examined with a DM 6000B fluorescence (Leica; Wetzlar, Germany), or an SP5 confocal (Leica) microscope.

$\beta$-Glucan Triggers Formation of NETs

\section{Determination of ROS Production}

$1 \times 10^{5}$ human or $7.5 \times 10^{5}$ mouse neutrophils were suspended in HGCa medium and were stimulated in black 96-well plates that had been previously precoated with $250 \mu \mathrm{g} / \mathrm{ml}$ human fibrinogen. Isoluminol-based chemiluminescence was assayed as previously described [26].

\section{Western Blotting}

Neutrophils $\left(10 \times 10^{6} / \mathrm{ml}\right)$ in HGCa were plated in 24-well plates precoated with human fibrinogen and stimulated with 50 $\mu \mathrm{g} / \mathrm{ml} \beta$-glucan or $20 \mathrm{ng} / \mathrm{ml}$ PMA for the time indicated in the results. At the appropriate time, cell activation was stopped by addition of $1 / 2$ volume of ice-cold HBSS (w/o Ca ${ }^{2+}$ and glucose) containing a 3 -fold concentration of protease inhibitors supplemented with $3 \mathrm{mM} \mathrm{Na}_{3} \mathrm{VO}_{4}, 30 \mathrm{mM}$ phenylarsine oxide, and $3 \mathrm{~mm}$ diisopropyl-fluorophosphate. Samples were kept in ice for $10 \mathrm{~min}$ before lysis with $4 \times$ sample buffer. Samples were separated on SDSPAGE gels and transferred to nitrocellulose Hybond C (Amersham). After quenching with 3\% BSA in TBS for $1 \mathrm{~h}$, blots were incubated overnight at $4^{\circ} \mathrm{C}$ with primary $\mathrm{Abs}$, followed by horseradish peroxidase-conjugated donkey anti-rabbit or goat antimouse Abs (Amersham). Immunoreactivity was detected using Immobilon Western detection reagent (Millipore) and analyzed with Quant Image LAS4000 (GE).

\section{Statistics}

Statistical significance of differences between the data was evaluated by ANOVA with Bonferroni posttests, which was performed using GraphPad Prism software. Values of $* \mathrm{p}<0.05,{ }^{* *} \mathrm{p}<0.01$ and ${ }^{* * *} \mathrm{p}<0.001$ were taken as significant.

\section{Results}

\section{Particulate $\beta$-Glucan Triggers NET Formation}

To examine the capability of the yeast cell wall component $\beta$-glucan to trigger NET formation, we used a particulate form of $\beta$-glucan. NETs induced by $\beta$-glucan particles were clearly visualized by fluorescence and confocal microscopy (fig. 1a, b). As shown with NETs induced by PMA and phagocytic particle $[1,11]$, NETs induced by $\beta$-glucan were stained by Abs against neutrophil granule constituents such as myeloperoxidase and elastase (fig. 1c). $\beta$-Glucan particles effectively triggered NET formation in a dose-dependent manner and, at the highest doses, their capability to induce NET formation was already detectable after $1 \mathrm{~h}$ following stimulation (fig. 2a). However, since in this study we compared the response to $\beta$-glucan with that to PMA, the most commonly used inducer of NET formation, whose effects are optimal after $3 \mathrm{~h}$ (fig. $2 \mathrm{a}$ and [11]), this time point was chosen for the below-described experiments. A comparison of the signal ensuing from binding of the cell-impermeable DNA dyes Sytox Green in intact versus Triton X-100-permeabilized cells showed that more than $30 \%$ $\beta$-glucan-stimulated neutrophils formed NETs (fig. $2 b$ ). 


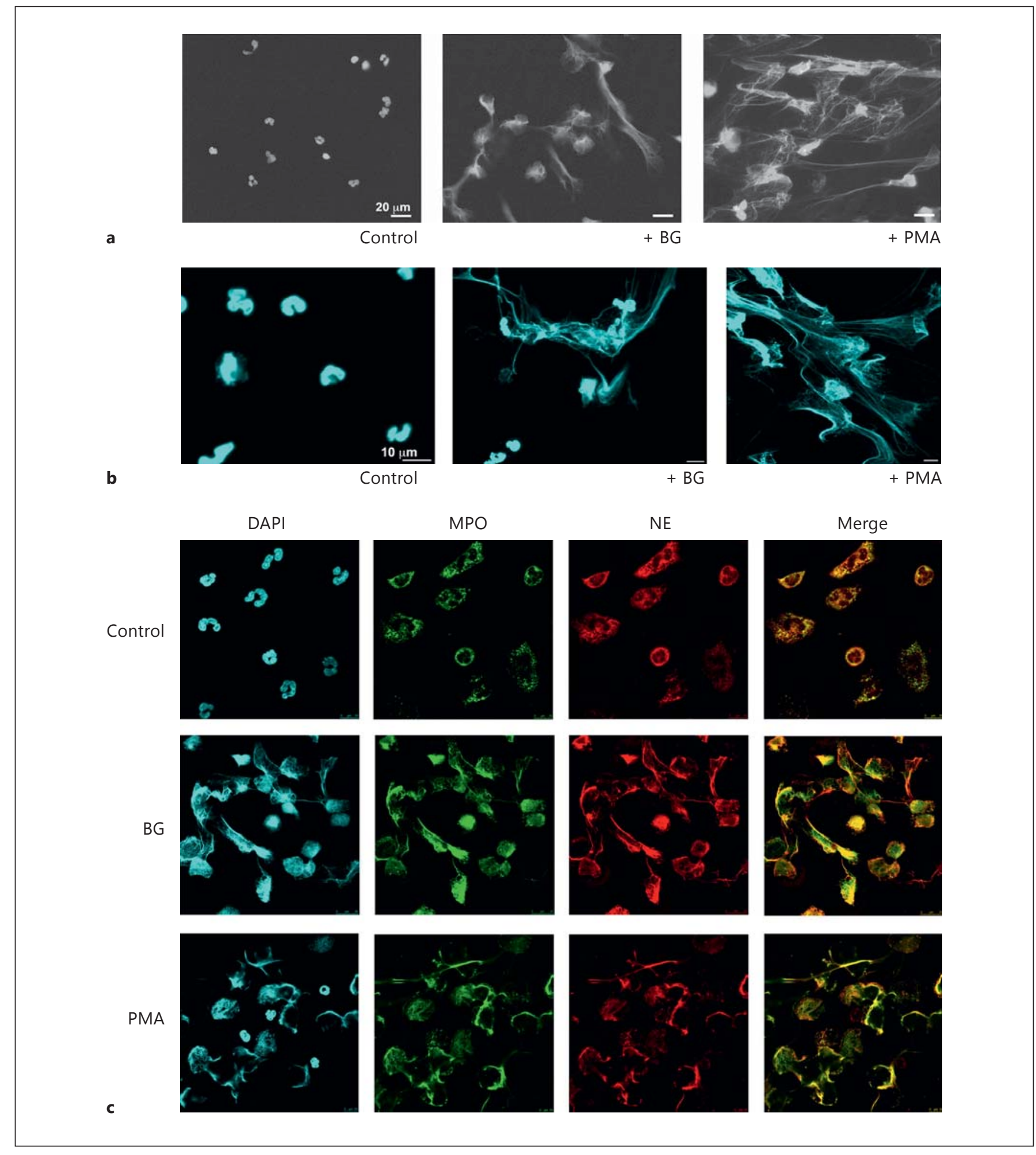

Fig. 1. $\beta$-Glucan (BG) particles induce NET formation. a Neutrophils were seeded on glass coverslips precoated with $0.01 \%$ poly-Llysine and incubated in the presence of $50 \mu \mathrm{g} / \mathrm{ml} \mathrm{BG}$ or $20 \mathrm{ng} / \mathrm{ml}$ PMA. After $3 \mathrm{~h}$, cells were fixed, permeabilized and stained with DAPI as described in Materials and Methods. NETs were visual- ized by fluorescence microscopy. Bars $=20 \mu \mathrm{m}$. b Neutrophils were treated as in a, and fluorescence analyzed by confocal microscopy. Bars $=10 \mu \mathrm{m}$. c Neutrophils were treated as described in a and stained with DAPI, myeloperoxidase and elastase as described in Materials and Methods.
62

J Innate Immun 2015;7:59-73 DOI: $10.1159 / 000365249$
Nani/Fumagalli/Sinha/Kamen/Scapini/ Berton 


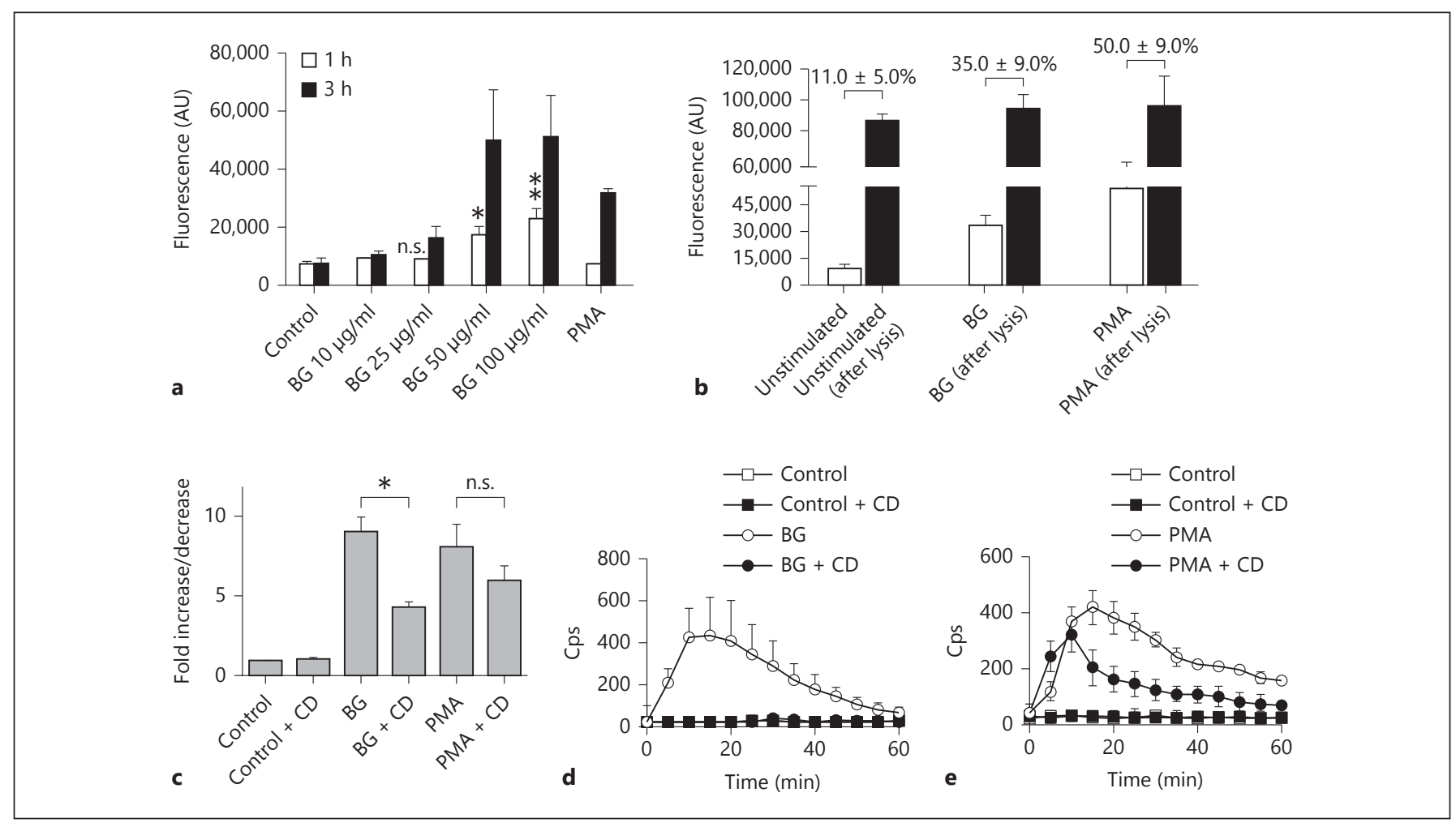

Fig. 2. CD inhibits NET formation in response to BG particles. a Neutrophils were incubated in 96-well fluorescence plates with different doses of BG particles or $20 \mathrm{ng} / \mathrm{ml}$ PMA as described in Materials and Methods. After 1 or $3 \mathrm{~h}$ of incubation, DNA was stained with SYTOX green and the fluorescence read after $5 \mathrm{~min}$. Mean results \pm SEM of 3 independent experiments are reported. ${ }^{*} \mathrm{p}<0.05,{ }^{* *} \mathrm{p}<0.01$, stimulated vs. unstimulated (control) cells. b Neutrophils were incubated for $3 \mathrm{~h}$ in the presence of $50 \mu \mathrm{g} / \mathrm{ml}$ BG or $20 \mathrm{ng} / \mathrm{ml}$ PMA and added with SYTOX green dissolved in PBS without or with $0.1 \%$ Triton X-100. The fluorescence was read

According to previous studies that demonstrated that only in a particulate form $\beta$-glucan is able to trigger the formation of a 'phagocytic synapse' that clusters receptors and signaling components in discrete plasma membrane region [27], we were unable to detect NET formation using soluble $\beta$-glucan (data not shown). Additionally, inhibition of phagosome formation by the cytoskeleton-disrupting agent cytochalasin D (CD) inhibited NET formation in response to $\beta$-glucan (fig. $2 \mathrm{c}$ ), but only marginally in response to PMA (fig. $2 \mathrm{~d}$ ). CD suppressed ROS generation in response to $\beta$-glucan particles (fig. $2 \mathrm{~d}$ ) and had some inhibitory effect on the delayed phase of ROS generation stimulated by PMA (fig. 2d). These findings suggest a quite strict correlation between ROS generation and NET formation, an issue that we addressed in great detail with experiments described below. after 10 min. Mean results \pm SEM of 3 independent experiments are reported. $\mathbf{c}$ Neutrophils were left untreated or incubated for 10 min at $37^{\circ} \mathrm{C}$ with $5 \mu \mathrm{g} / \mathrm{ml} \mathrm{CD}$ and then added or not with $50 \mu \mathrm{g} /$ $\mathrm{ml} \mathrm{BG}$ or $20 \mathrm{ng} / \mathrm{ml}$ PMA. After $3 \mathrm{~h}$ of incubation, DNA was stained with SYTOX green and the fluorescence read after 5 min. Mean results \pm SEM of 3 independent experiments are reported. * $p<$ 0.05. d, e Samples of the same cells used for assays of NET formation were assayed for ROS generation by chemiluminescence as described in Materials and Methods.

\section{Src Family Kinases Are Implicated in}

\section{$\beta$-Glucan-Induced NET Formation}

$\beta$-Glucan particles have been described to be recognized by different receptors including the C-type lectin Dectin-1, CR3 ( $\alpha \mathrm{M} \beta_{2}$ integrin) and the scavenger receptor CD36; notably, all these receptors share a common signaling pathway implicating Src family kinases, ITAM sequences and the tyrosine kinase Syk (see Introduction). In order to elucidate the role of Src family kinases in $\beta$-glucan-induced NET formation in human neutrophils, we examined the effect of Src family kinase inhibitors on this response.

As illustrated in figure $3 a$ and $b$, the Src family kinase inhibitor PP2 and the Src/Abl dual specificity inhibitor dasatinib strongly reduced NET formation in response to $\beta$-glucan. Given that ROS have been reported to play an 
essential role in NET formation $[11,28]$, we asked whether the inhibitory effect of PP2 on $\beta$-glucan particle-induced NET formation went in parallel with inhibition of ROS generation. Indeed, we found that PP2 inhibited both ROS generation and NET formation in neutrophils challenged with $\beta$-glucan (fig. 3). Similar results were obtained with dasatinib (fig. $3 \mathrm{~b}$ and data not shown). Notably, formation of NETs in response to PMA was not affected by Src kinase inhibitors (fig. 3a, b). Considering that PMA triggers ROS generation in an Src family kinase-independent [29], PP2-insensitive manner (fig. 3c), we conclude that, independently of the signaling pathway leading to their formation, ROS are required for NET formation.

To strengthen the evidence that NET formation in response to $\beta$-glucan requires ROS generation we examined the effects of the NADPH oxidase inhibitor DPI that, as expected, suppressed ROS generation in our experimental conditions both in response to $\beta$-glucan and PMA (data not shown). DPI inhibited NET formation in response to $\beta$-glucan and, in agreement with previous reports $[11,28]$, had a totally inhibitory effect on NET formation in response to PMA (fig. 3a, b). The findings illustrated in figure 3 suggest that within the signaling pathwayleading to NET formation in response to $\beta$-glucan particles, Src kinases are upstream of ROS, whereas PMA, due to its capability to impinge on diacylglycerol-dependent protein kinase $\mathrm{C}$ isoforms, activates $\mathrm{NADPH}$ oxidase directly. Independently of the distinct signaling pathways triggered by $\beta$-glucan particles and PMA, ROS generation seems to be required for an optimal formation of NETs in response to both stimuli. However, it is worth noting that whereas DPI suppressed NET formation in response to PMA, it did not completely inhibit the response to $\beta$-glucan (fig. $3 \mathrm{a}, \mathrm{b}$ ). These findings point to the existence of ROS-independent pathways that may even predominate depending on the experimental system used (see [16]).

Fig. 3. NET formation induced by BG particles requires Src family kinase activities and ROS generation. a Neutrophils were seeded on glass coverslips precoated with $0.01 \%$ poly-L-lysine and, after preincubation for $10 \mathrm{~min}$ at $37^{\circ} \mathrm{C}$ with $10 \mu \mathrm{M} \mathrm{PP} 2$ or $20 \mu \mathrm{M} \mathrm{DPI}$, stimulated with $50 \mu \mathrm{g} / \mathrm{ml} \mathrm{BG}$ or $20 \mathrm{ng} / \mathrm{ml}$ PMA. After $3 \mathrm{~h}$, cells were fixed, permeabilized and stained with DAPI as described in Materials and Methods. NETs were visualized by fluorescence microscopy. Bars $=50 \mu \mathrm{m}$. b Neutrophils were preincubated with 10 $\mu \mathrm{M}$ PP2, $20 \mu \mathrm{M}$ DPI or $1 \mu \mathrm{M}$ dasatinib in 96-well fluorescence plates and then stimulated with $50 \mu \mathrm{g} / \mathrm{ml} \mathrm{BG}$ particles or $20 \mathrm{ng} / \mathrm{ml}$ PMA. After $3 \mathrm{~h}$ of incubation, DNA was stained with SYTOX green and
Mechanisms of Activation of Src Family Kinases and Syk by $\beta$-Glucan Particles and PMA

To better elucidate the role of Src family kinases in the response to $\beta$-glucan, we examined their phosphorylation status utilizing an $\mathrm{Ab}$ raised against a tyrosine residue present within the kinase domain of Lyn, whose phosphorylation correlates with the kinase activity [30]. As shown in figure $4 \mathrm{a}$, this phospho-specific $\mathrm{Ab}$ allowed us to detect a time-dependent increase in both Lyn and Hck phosphorylation in neutrophils stimulated with $\beta$-glucan; PP2 suppressed this response. Consistent with several reports showing stimulation of tyrosine phosphorylation signals by PMA [see 31 and reference contained therein], also this stimulus triggered Lyn and Hck phosphorylation in a PP2-dependent manner (fig. 4b). In light of evidence implicating ROS in activation of Src kinases [32] we also addressed whether treatment with DPI exerted an inhibitory effect on Lyn and Hck phosphorylation and found that it blunted Src family kinase activation in response to both $\beta$-glucan and PMA (fig. $4 c, d$ ).

The evidence that PP2 did not affect PMA-induced NET and ROS formation (fig. 3) despite its ability to suppress PMA-induced Src kinase activation (fig. 4b) clearly shows that activation of Src kinases by PMA plays no role in NET formation. Intriguingly, the data presented in figure 4 pointed to an essential role of ROS also in $\beta$-glucaninduced Lyn and Hck activation, an unexpected finding in light of the evidence that PP2 inhibits $\beta$-glucaninduced ROS generation (fig. 3) thus placing Src kinases upstream of ROS in this response. Considering that failure to detect phosphorylation of Lyn and Hck with the anti-Lyn Ab specific for the phosphoY396 residue could not necessarily reflect a total absence of Src family kinase activities and with this Ab we did not detect phosphorylation of Fgr (see legend to fig. 4), another Src family kinase member expressed at high levels in myeloid leukocytes, we extended our analysis to the Src downstream targets Syk and Vav.

the fluorescence read after 5 min. Mean results \pm SD of 5 (BG and PMA without or with PP2/DPI) or 4 (BG and PMA without or with Dasatinib) independent experiments are reported. The experiments plotted in the two panels were performed with different batches of cells. Data are expressed as fold increase/decrease of the fluorescence detected with nonstimulated (control) cells incubated in the absence of any inhibitor, whose SYTOX green fluorescence was set to a value of $1 .{ }^{*} \mathrm{p}<0.05$; ${ }^{* * *} \mathrm{p}<0.001$; n.s. $=$ Not significant. c Samples of the same cells used in the upper panel of b were assayed for ROS generation by chemiluminescence as described in Materials and Methods.

(For figure see next page.)
Nanì/Fumagalli/Sinha/Kamen/Scapini/ Berton 


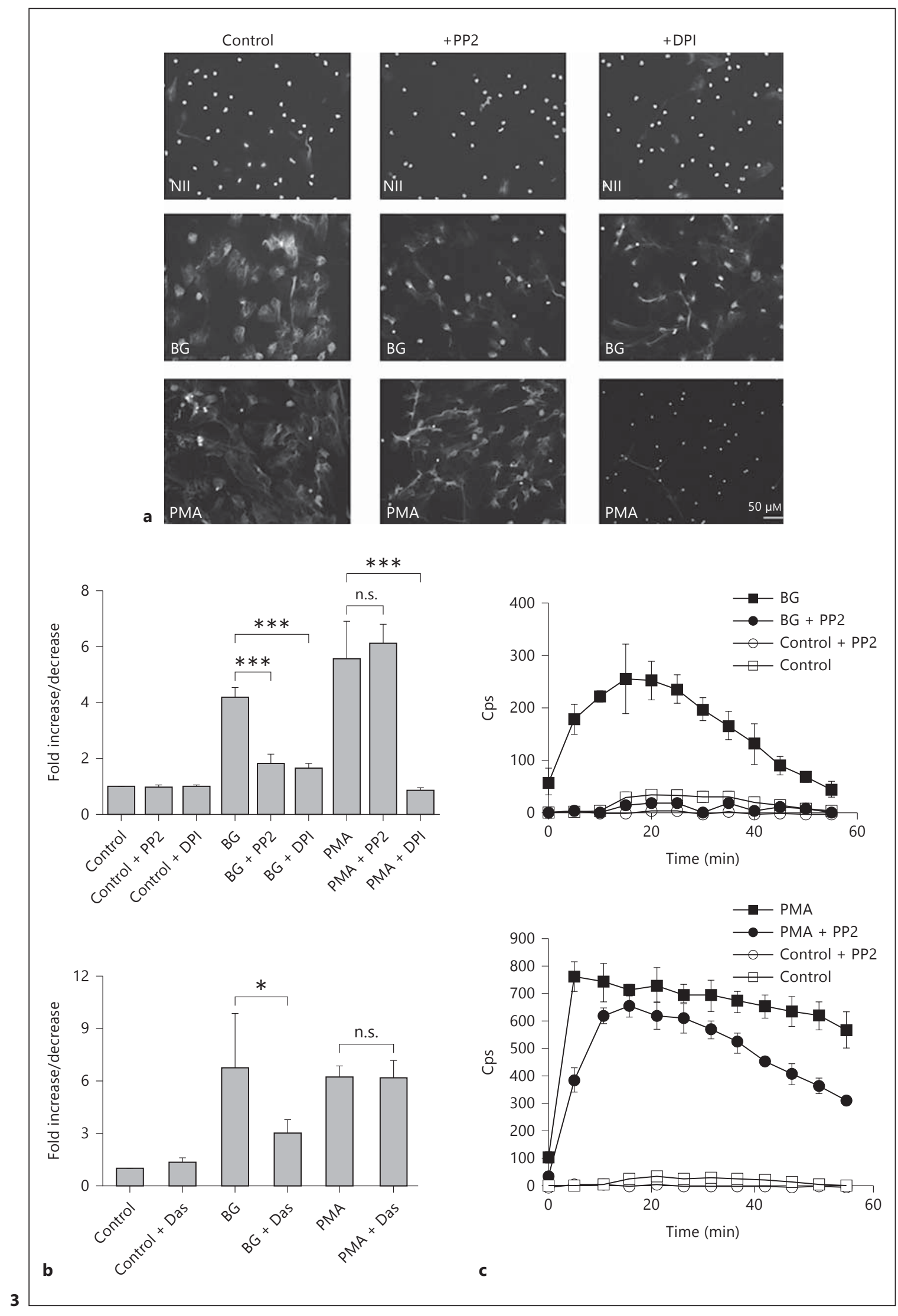


Examining Syk phosphorylation in two tyrosine residues placed within its activation loop and whose phosphorylation correlates with Syk kinase activity [33], we detected a time-dependent and prolonged (up to $60 \mathrm{~min}$ ) Syk phosphorylation in human neutrophils challenged with particulate $\beta$-glucan (fig. 5). Notably, suppression of ROS generation by DPI only partially inhibited Syk phosphorylation (fig. 5a) and had no effect on phosphorylation of the Src/Syk substrate Vav (fig. 5b). In contrast, the Src kinase inhibitor PP2 suppressed tyrosine phosphorylation of both Syk and Vav (fig. 5c, d). These findings suggest that, by targeting Src kinases, PP2 inhibits the $\beta$-glucan-stimulated Src/Syk signaling pathway that is upstream of ROS generation (fig. 3).

Differently from $\beta$-glucan and in line with the capability of ROS to activate Syk in leukocytes [34], modulation of the Src/Syk signaling pathway by PMA is totally dependent on ROS; in fact, both Syk and Vav tyrosine phosphorylation in response to PMA was suppressed by DPI (fig. 5e, f).

\section{NET Formation Is Prevented by the Syk Inhibitor PRT-060318}

To address the role of Syk in NET formation, we used inhibitors described as selective for Syk. Initially, we examined the effect of piceatannol, a compound that has been used in several studies as a selective Syk inhibitor [see 35]. As illustrated in figure 6a, piceatannol suppressed NET formation in response to both $\beta$-glucan and PMA, suggesting the bona fide conclusion that Syk is essential for NET formation in response to two unrelated stimuli. However, considering that piceatannol was also described as a potent antioxidant [36], we wondered whether it could reduce ROS formation. Notably, we found that piceatannol suppressed ROS generation in response to both $\beta$-glucan and PMA (fig. 6b). Considering that ROS play an essential role in NET formation in response to PMA (fig. 3 and $[11,28]$ ), we therefore conclude that piceatannol does not fulfill the criteria to be used exclusively as a selective Syk inhibitor.

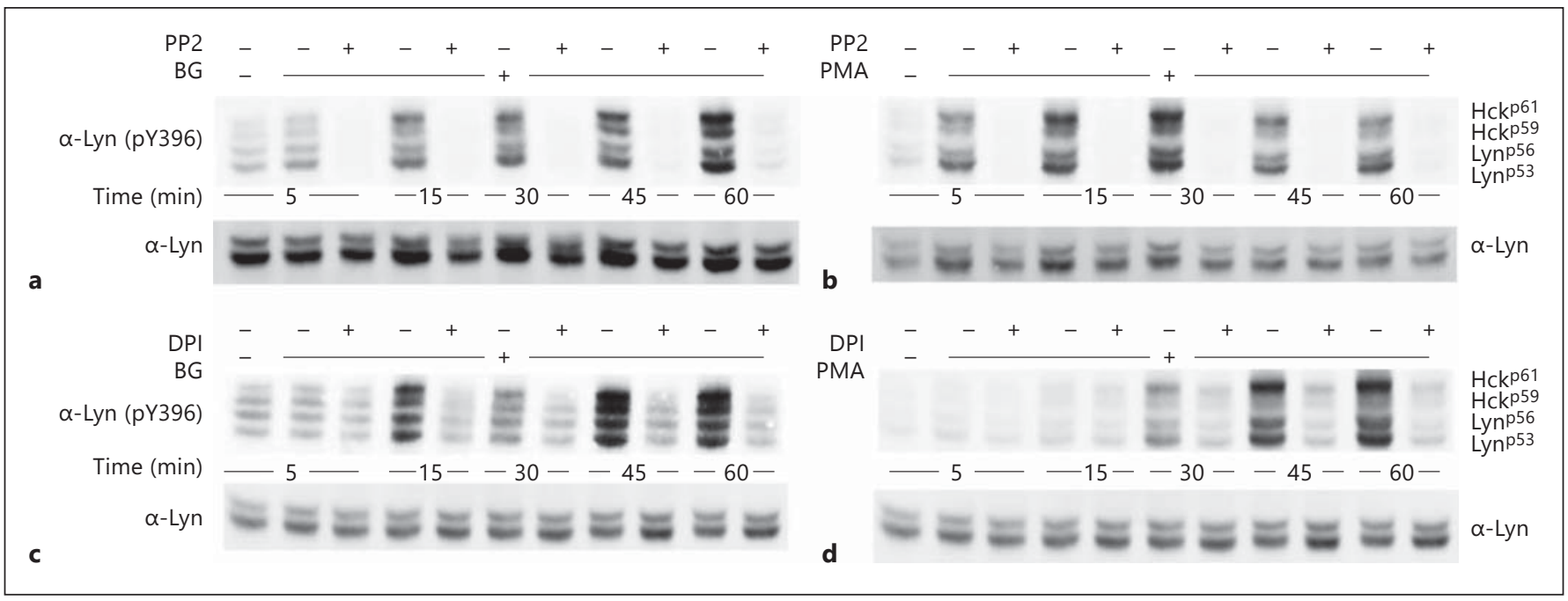

Fig. 4. BG particles and PMA trigger Lyn and Hck phosphorylation. Neutrophils were plated in fibrinogen-coated 24-well plates and after preincubation for $10 \mathrm{~min}$ at $37^{\circ} \mathrm{C}$ with $10 \mu \mathrm{M}$ PP2 (a, b) or $20 \mu \mathrm{M}$ DPI (c, d), stimulated with $50 \mu \mathrm{g} / \mathrm{ml} \mathrm{BG}(\mathbf{a}-\mathbf{c})$ or $20 \mathrm{ng} /$ ml PMA (b-d). After different times, cells were lysed and lysates subjected to immunoblot analysis with Abs of the specificity indicated on the left of the figure, as described in Materials and Meth-

Fig. 5. BG particles and PMA trigger Syk and Vav phosphorylation. Neutrophils were plated in fibrinogen-coated 24-well plates and after preincubation for $10 \mathrm{~min}$ at $37^{\circ} \mathrm{C}$ with $20 \mu \mathrm{M} \mathrm{DPI} \mathrm{(a,} \mathrm{b,}$ e, f) or $10 \mu \mathrm{M} \mathrm{PP} 2$ (c, d), stimulated with $50 \mu \mathrm{g} / \mathrm{ml} \mathrm{BG}$ (a-d) or 20 $\mathrm{ng} / \mathrm{ml}$ PMA (e, f). After different times, cells were lysed and lysates ods. Migration of the two isoforms of Hck and Lyn detected in the same blot with anti-protein Abs is indicated on the right of the panel. Phosphorylation of the Fgr protein - which migrates between the $\mathrm{Hck}^{\mathrm{p} 59}$ and the $\mathrm{Lyn}^{\mathrm{p} 56}$ isoforms (data not shown) - is not detected by the anti-Lyn (pY396) Ab. One representative of 2-3 experiments performed is reported.

subjected to immunoblot analysis with Abs of the indicated specificity as described in Materials and Methods. One representative of 2-3 experiments performed is reported. Histograms on the right of the immunoblots report densitometric analysis, expressed as the ratio between the phosphoprotein and the total protein signal.

(For figure see next page.)
66
J Innate Immun 2015;7:59-73 DOI: $10.1159 / 000365249$
Nanì/Fumagalli/Sinha/Kamen/Scapini/ Berton 


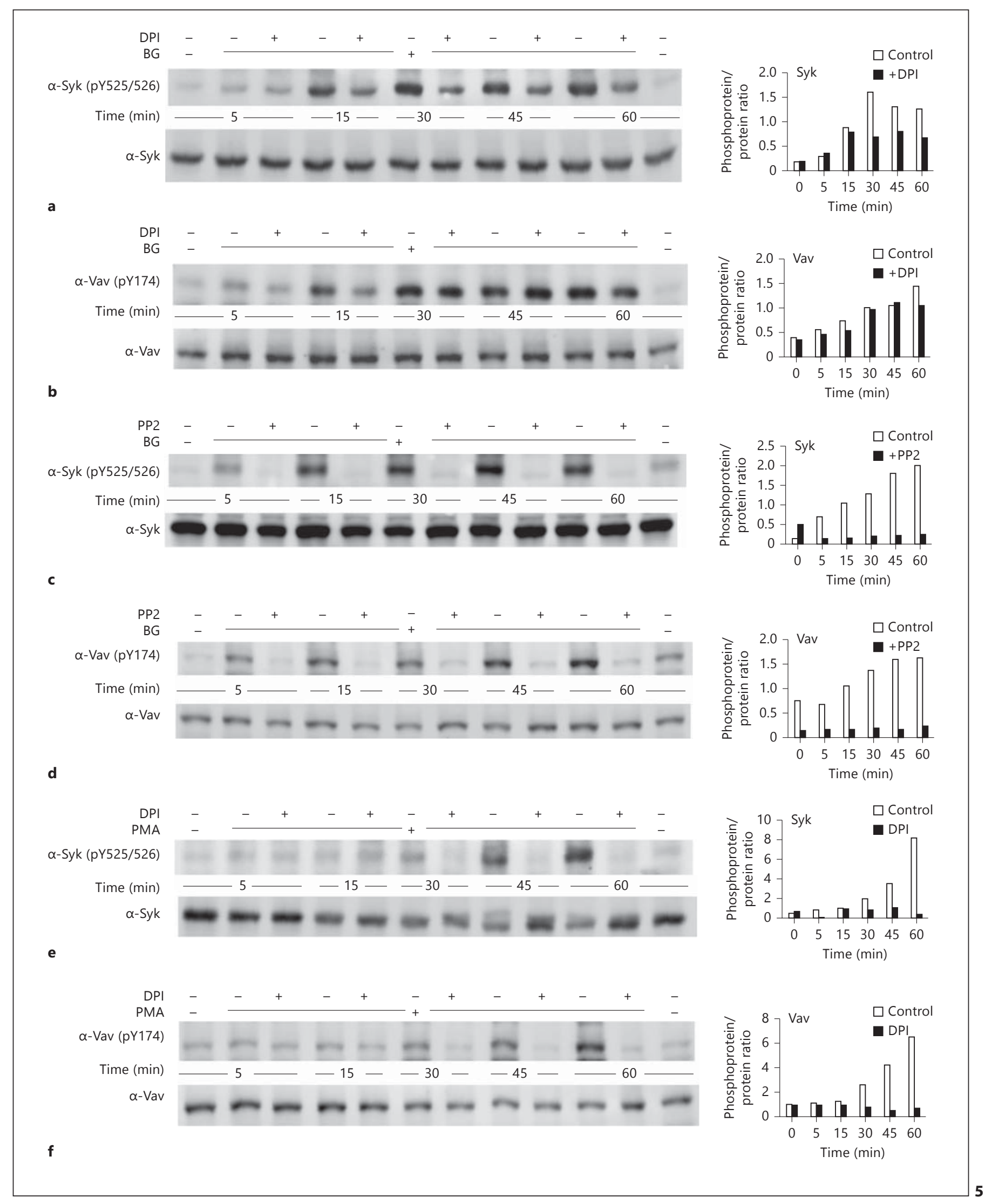

$\beta$-Glucan Triggers Formation of NETs 
Recent studies described a novel Syk selective inhibitor, PRT-060318, that markedly reduces stimulation of platelet responses via the ITAM module signaling receptor for collagen glycoprotein VI [37], so we addressed whether it inhibited NET formation. Notably, at a dose of $1 \mu \mathrm{M}$, PRT-060318 totally suppressed Syk phosphorylation in response to $\beta$-glucan and PMA (fig. $6 c, d$ ). Whereas PRT-060318 markedly reduced NET formation induced by $\beta$-glucan (fig. 6e), its capability to inhibit the response to PMA was lower $(40.4 \pm 14 \%$ inhibition, $n=$ $5)$, but the difference between untreated and PRT060318-treated neutrophils was statistically significant (fig. 6e). Notably, at these doses, ROS generation in response to $\beta$-glucan was suppressed by PRT-060318 (fig. 6f); however, this compound had no effect on the response to PMA (fig. 6g). We conclude that, as also suggested from studies with the Src inhibitor PP2 (fig. 3), $\beta$-glucan triggers the Src/Syk signaling pathway upstream of ROS formation. In contrast, and in agreement with the data obtained inhibiting Src kinases with PP2 (fig. 3), ROS generation triggered by PMA is independent of Syk. The evidence that, in response to PMA, PRT-060318 did not affect ROS generation but inhibited NET formation to some extent suggests that the mechanisms of action of PMA may, at least in part, depend on the capability of ROS to activate Syk.

\section{Deficiency of Syk Results in Suppression of NET}

Formation in Response to $\beta$-Glucan in Murine

Neutrophils

In order to strengthen the notion that the signaling pathwayleading to NET formation in response to $\beta$-glucan requires Syk, we examined this response in control and $s y k^{-/-}$neutrophils. Although we hardly detected NET formation in murine neutrophils in response to PMA (data not shown), particulate $\beta$-glucan triggered NET formation in murine neutrophils (fig. 7). In fact, in $\beta$-glucan-

Fig. 6. NET formation induced by BG particles requires the Syk kinase activity. a Neutrophils were preincubated with $50 \mu \mathrm{M}$ piceatannol in 96-well fluorescence plates and then stimulated with $50 \mu \mathrm{g} / \mathrm{ml} \mathrm{BG}$ particles or $20 \mathrm{ng} / \mathrm{ml}$ PMA. After $3 \mathrm{~h}$ of incubation, DNA was stained with SYTOX green and the fluorescence read after 5 min. Mean results \pm SD of 3 independent experiments are reported. $\mathbf{b}$ Samples of the same cells used in $\mathbf{a}$ were assayed for ROS generation by chemiluminescence as described in Materials and Methods. c, d Neutrophils were plated in fibrinogen-coated 24-well plates and after preincubation for $10 \mathrm{~min}$ at $37^{\circ} \mathrm{C}$ with $1 \mu \mathrm{M}$ PRT-060318 stimulated with $50 \mu \mathrm{g} / \mathrm{ml} \mathrm{BG}$ (c) or $20 \mathrm{ng} / \mathrm{ml}$ PMA (d). After different times, cells were lysed and lysates subjected to immunoblot analysis with Abs of the indicated specific- stimulated murine neutrophils, nuclei lost their typical lobulated structure seen in nonstimulated cells (fig. 7a) and appeared as flattened and enlarged, homogenous masses forming veil-like structures (fig. 7b). Additionally, staining with anti-elastase Abs showed a typical granular pattern in nonstimulated neutrophils (fig. 7c), but a diffuse pattern over flattened nuclei and veil-like structures in $\beta$-glucan-stimulated cells (fig.. 7d). Notably, comparing control versus Syk-deficient neutrophils, we found that $s y k^{-/-}$neutrophils were unable to exteriorize DNA (fig. 7e) or elastase (fig. 7f) in response to $\beta$-glucan.

In order to strengthen the notion emerging from the results of inhibitory studies illustrated in figures 2,3 and 6 , we also addressed whether $s y k^{-/-}$neutrophils were defective in ROS generation in response to $\beta$-glucan. Consistently with the evidence that Syk deficiency results in defective integrin-dependent ROS generation, but does not affect responses triggered by trimeric $\mathrm{G}$ protein-coupled receptor $[38,39]$, we found that the early adhesionindependent $\mathrm{fMLP}$-induced phase of ROS generation [see 26] was equal in wild-type and Syk-deficient neutrophils (fig. 7g). However, both the late fMLP-induced adhesion-dependent response (fig. $7 \mathrm{~g}$ ) and the $\beta$-glucaninduced response (fig. $7 \mathrm{~h}$ ) were totally defective in $s y k^{-/-}$ neutrophils.

\section{Discussion}

In this report, we addressed signal transduction pathways implicated in NET formation by $\beta$-glucan particles. According to previous data using intact fungi [15] and purified $\beta$-glucan [16], we detected a strong formation of NETs in neutrophils exposed to $\beta$-glucan particles. However, differently from the last study, our assay conditions allowed us to detect NET formation in response to $\beta$-glucan without the need of priming the cells or coexpo-

ity as described in Materials and Methods. One representative of $2-3$ experiments performed is reported. e Neutrophils were preincubated with $1 \mu \mathrm{M}$ PRT-060318 in 96-well fluorescence plates and then stimulated with $50 \mu \mathrm{g} / \mathrm{ml} \mathrm{BG}$ particles (BG) or $20 \mathrm{ng} / \mathrm{ml} \mathrm{PMA}$. After $3 \mathrm{~h}$ of incubation, DNA was stained with SYTOX green and the fluorescence read after $5 \mathrm{~min}$. Mean results \pm SD of 5 independent experiments are reported. Data are expressed as fold increase/ decrease of the fluorescence detected with nonstimulated cells incubated in the absence of any inhibitor, whose SYTOX green fluorescence was set to a value of $1 .^{* *} \mathrm{p}<0.01$; $^{* *} \mathrm{p}<0.001 . \mathbf{f}, \mathbf{g}$ Samples of the same cells used in the experiments reported in $\mathbf{e}$ were assayed for ROS generation by chemiluminescence as described in Materials and Methods.

(For figure see next page.)
68
J Innate Immun 2015;7:59-73 DOI: $10.1159 / 000365249$
Nanì/Fumagalli/Sinha/Kamen/Scapini/ Berton 
sure to fibronectin. In fact, we detected NETs both by Sytox-Green staining of unprimed neutrophils plated in fibrinogen-coated plates and by DAPI staining of cells plated on poly-L-lysine. One possible important difference between our own study and the one by Byrd et al.
[16] is the use by us of phagocytosable $\beta$-glucan particles and not surface-bound $\beta$-glucan. It is important to note that adherence of neutrophils to surface-bound ligands represents what has been considered for a long time as a sort of 'frustrated phagocytosis'. Indeed, also in the con-
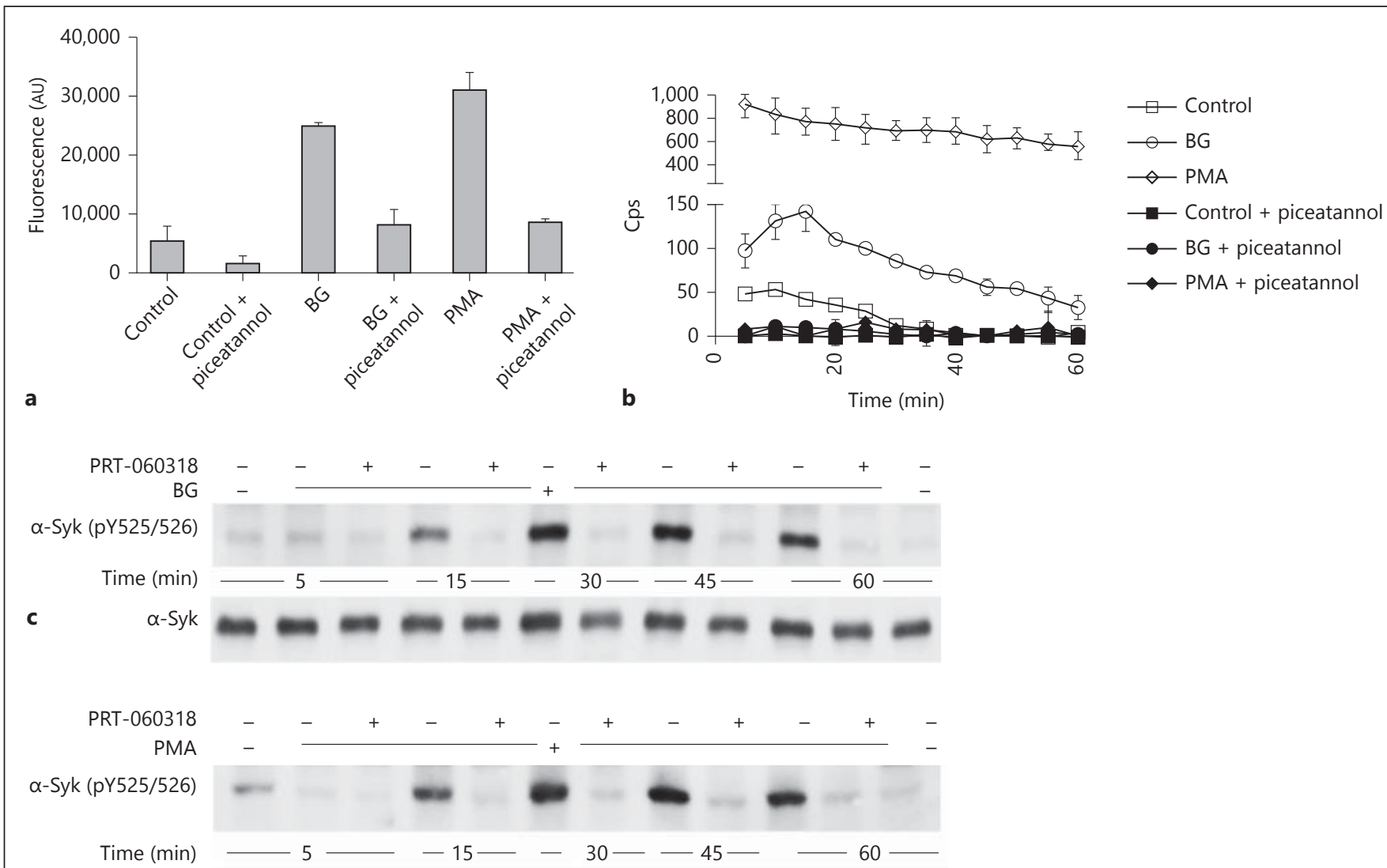

d

$$
\alpha-S y k
$$$$
-\infty-\infty \mathrm{es}
$$

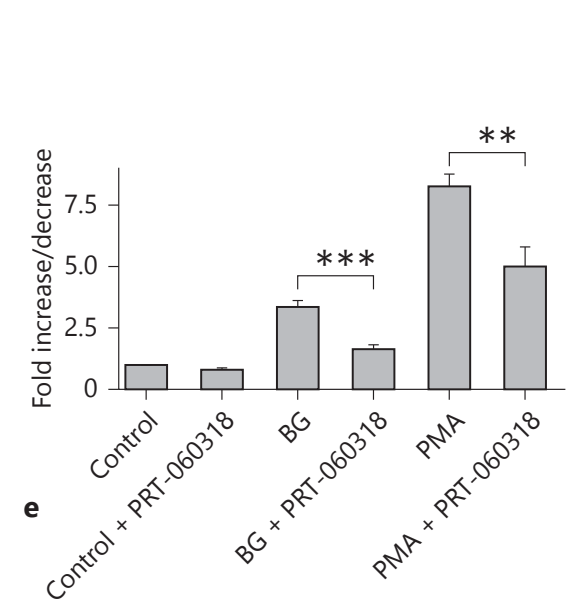

$$
\begin{aligned}
& \bigcirc-B G
\end{aligned}
$$

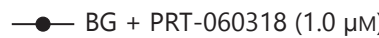

$$
\begin{aligned}
& \rightarrow \text { PRT-060318 } \\
& \text { 曰- Control }
\end{aligned}
$$

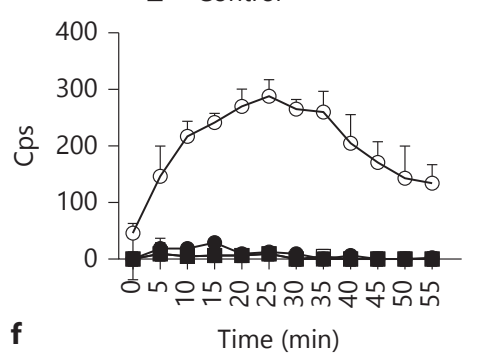

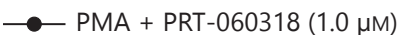

$\rightarrow$ PRT-060318

$\square$ Control

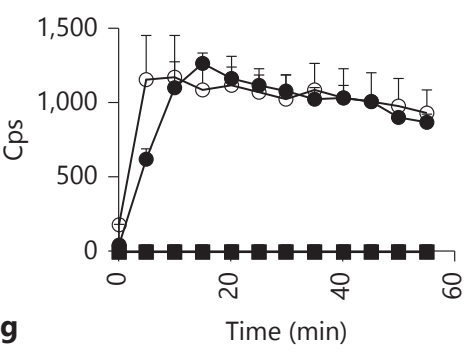


text of $\beta$-glucan stimulation of innate immunity cell responses, surface-bound $\beta$-glucan triggers cytokine and ROS release [27]. However, surface-bound $\beta$-glucan is unable to trigger NET formation despite its ability to stimulate ROS generation [16]. Although this issue goes beyond the scope of our paper, it is tempting to speculate that triggering NET formation by pathogen receptors requires ROS formation but also phagosome formation and the subsequent fusion of lysosomes with it. This could somehow favor the release in the cytoplasm and translocation to the nucleus of granule proteins such as elastase and myeloperoxidase, which have been shown to be essential for chromatin decondensation and NET formation [12]. In this context, it is of great interest that NET formation induced by immune complexes was also reported to require endocytosis and was not induced by their surface-bound form [40]. Notably, inhibition of endocytosis by the microfilament-disrupting agent $\mathrm{CD}$, blocked NET formation induced by immune complexes [40] or $\beta$-glucan (fig. 2). PMA, the most powerful inducer of NETs, may act due to its capability to trigger elevated amounts of ROS and/or to activate still unidentified pathways bypassing the requirement for phagosome-lysosome fusion. However, as pointed out by Brinkmann and Zychlinsky [2], PMA is known to induce the formation of vacuoles. Whether these fuse with lysosomes favoring the eventual leakage of elastase and myeloperoxidase (see above) and their targeting to the nucleus has not yet been addressed. While phagocytosis of particles or vacuole formation seems to be required for NET formation, the demonstration that this can occur also in response to coexposure to surface-bound $\beta$-glucan and fibronectin [16] points to the existence of additional, phagocytosis-independent mechanisms of NET formation.

Our findings show that the signaling pathway implicated in NET formation following $\beta$-glucan particle internalization implicates Src family kinases/Syk and ROS. $\beta$-Glucan particles triggered a prolonged phosphorylation of Lyn and Hck in a tyrosine residue whose phos-

Fig. 7. Neutrophils deficient in Syk are defective in formation of NETs and ROS generation in response to BG particles. a-d Control (Sykfff and/or Vav1cre $e^{T g}$ mice; see Materials and Methods) and syk $k^{-/}$ $(\mathbf{e}, \mathbf{f})$ neutrophils were seeded on glass coverslips precoated with $0.01 \%$ poly-L-lysine and stimulated or not with $35 \mu \mathrm{g} / \mathrm{ml} \mathrm{BG}$. After $3 \mathrm{~h}$, cells were fixed, permeabilized and stained with DAPI $(\mathbf{a}, \mathbf{b}, \mathbf{e})$ or anti-elastase Abs $(\mathbf{c}, \mathbf{d}, \mathbf{f})$ as described in Materials and Methods. Image magnification was $\times 200$ for $\mathbf{a}, \mathbf{b}, \mathbf{e}($ bars $=100 \mu \mathrm{m})$ and $\times 400$ for $\mathbf{c}, \mathbf{d}, \mathbf{f}($ bars $=50 \mu \mathrm{m})$. Note that, compared with $s y k^{-/-}$neutrophils phorylation correlates with the kinase activity. The Src kinase inhibitor PP2 suppressed activation of both kinases (fig. 4) as well as the downstream components Syk and Vav (fig. 5). ROS generation induced by $\beta$-glucan is absolutely dependent on Src and Syk. In fact, both PP2 (fig. 3) and the Syk inhibitor PRT-060318 (fig. 6) suppressed ROS generation in response to $\beta$-glucan. However, the evidence that suppression of ROS generation by DPI inhibited Lyn and Hck phosphorylation (fig. 4) suggests that ROS act within a positive feedback circuit regulating, at least, Lyn and Hck activation. Notably, DPI only partially inhibited Syk and had no effect on Vav phosphorylation (fig. 5) indicating that other Src kinases, not detected with the anti-Lyn phospho Y396 Ab, could be activated by $\beta$-glucan. At present, we do not know whether the evidence that PP2 suppresses Syk phosphorylation and the Src/Syk downstream target Vav (fig. 5, 6) is due exclusively to its capability to effectively inhibit all Src kinases expressed in neutrophils or also to target Syk. Independent of its mechanisms of activation, studies with murine Syk-deficient neutrophils demonstrated an important role of Syk in triggering NET formation in response to Staphylococcus aureus and Escherichia coli [25], as well as immune complexes [41]. Our finding that also the response to $\beta$-glucan is defective in Syk-deficient neutrophils strengthens the conclusion that Syk regulates NET formation in response to different agonists.

Several findings point to an indispensable role of ROS in $\beta$-glucan particle-induced NET formation. Firstly, inhibition of ROS formation by DPI markedly inhibited this response (fig. 3). Secondly, ROS generation always correlated with NET formation, and inhibition of ROS generation by the microfilament-disrupting agent CD (fig. 2), the Src kinase inhibitor PP2 (fig. 3) or the Syk inhibitor PRT-060318 (fig. 6) also resulted in an impaired formation of NETs. Finally, piceatannol, a compound acting as a ROS scavenger [36] suppressed both ROS generation and NET formation. We conclude that, as demonstrated in early studies using PMA as a stimulus $[11,28]$, ROS are indispensable for an optimal formation of NETs in re-

(e), control(b) neutrophils challenged with BG havelost their typical lobulated nuclei, and nuclei appear as flattened and enlarged, homogenous masses forming veil-like structures. Staining with antielastase Abs (green) shows a diffuse pattern of staining over flattened nuclei and veil-like structures in control (d) neutrophils and a typical granular pattern in $S y k^{-/-}$neutrophils (f). $\mathbf{g}, \mathbf{h}$ Aliquots of cells used for the experiments reported in panels a-f were assayed in triplicates for ROS generation as described in Materials and Methods. One of two experiments performed with equal results is reported.

(For figure see next page.)
Nanì/Fumagalli/Sinha/Kamen/Scapini/ Berton 


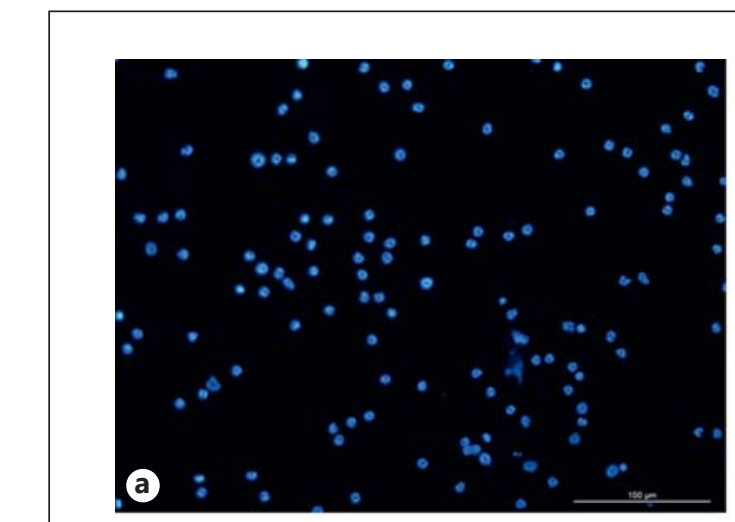

Control neutrophils (untreated)

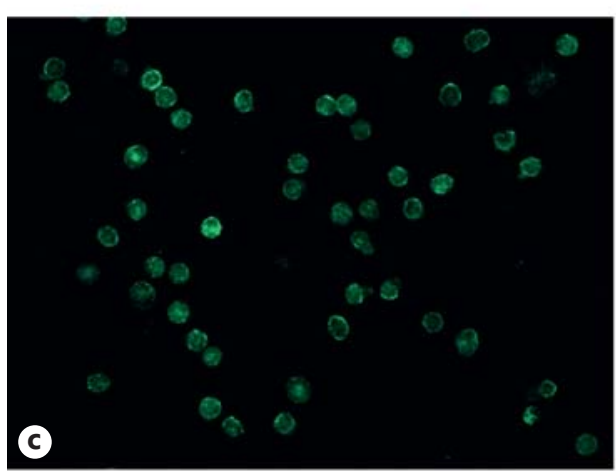

Control neutrophils (untreated)

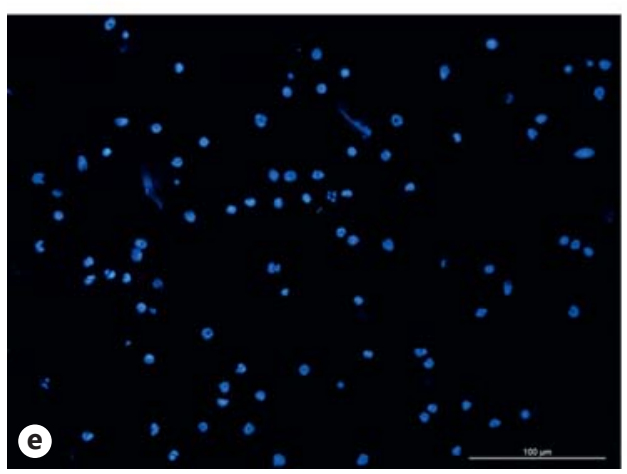

Syk ${ }^{-1-}$ neutrophils (+ BG)

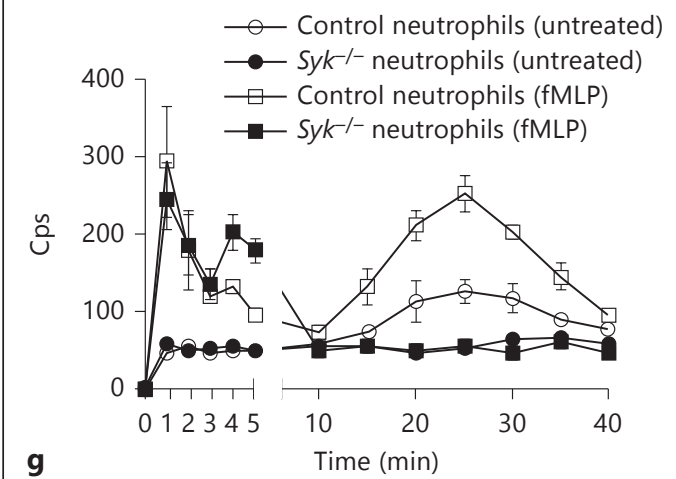

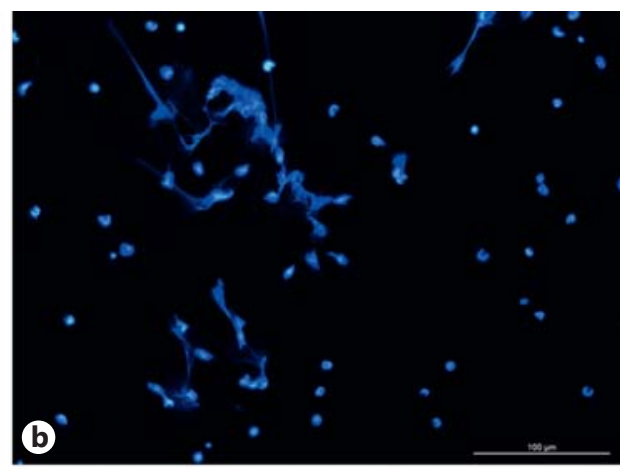

Control neutrophils (+ BG)

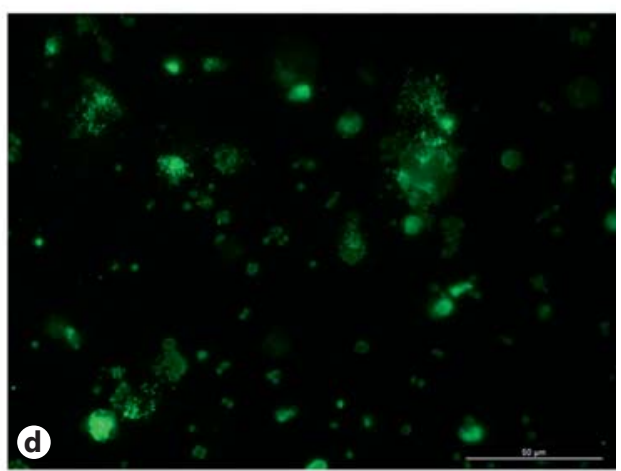

Control neutrophils (+ BG)

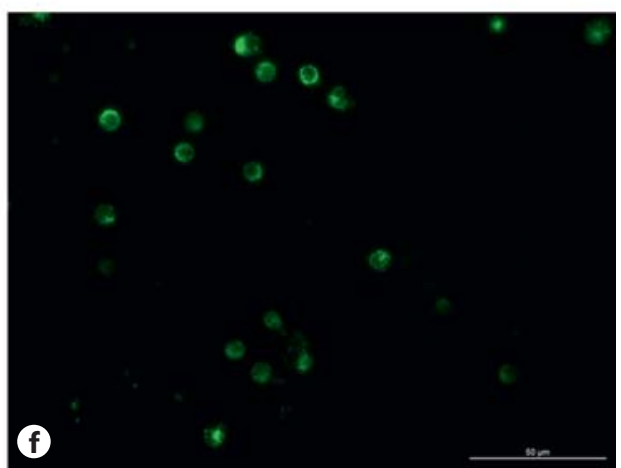

Syk ${ }^{-/-}$neutrophils (+ BG)

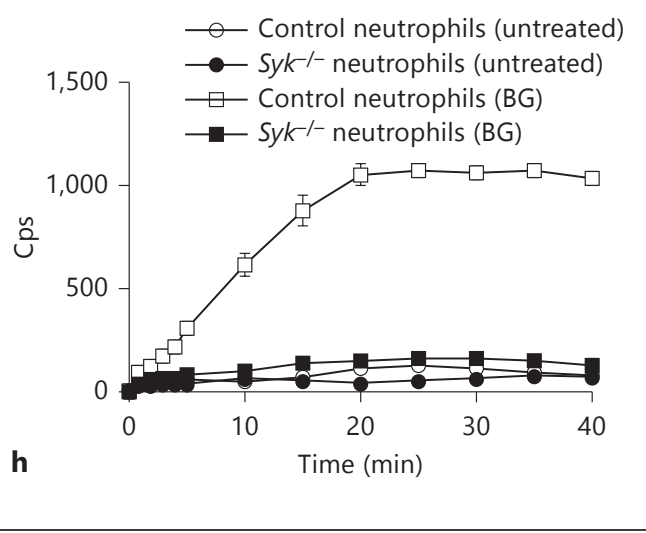


sponse to $\beta$-glucan particles. However, it is worth noting that whereas DPI suppressed NET formation in response to PMA, it did not completely inhibit the response to $\beta$-glucan (fig. 3a, b). These findings point to the existence of ROS-independent pathways that may even predominate depending on the experimental system used [see 16].

Based on our findings, the direct stimulation of ROS generation via activation of protein kinase $\mathrm{C}$ by PMA bypasses the requirement for the Src-dependent signaling pathway activated by $\beta$-glucan particles. In fact, even though PMA impinges on Src via formation of ROS (fig. 4), inhibition of Src kinases by PP2 (fig. 3) has no effect on PMA-induced ROS generation and NET formation. Consistently, inhibitors of PMA-induced NET formation such as DPI (fig. 3) or piceatannol (fig. 6) also suppressed ROS generation. It is worth noting that we obtained evidence that the mechanism of action of ROS in PMA-induced NET formation goes, at least in part, through their capability to activate Syk (fig. 5, 6). In fact, inhibition of Syk with PRT-060318 had no effect on ROS generation, but inhibited in part NET formation.

$\beta$-Glucan is recognized by innate immunity cells via different receptors including the C-type lectin Dectin-1, CR3 ( $\alpha \mathrm{M} \beta_{2}$ integrin) and the scavenger receptor CD36; notably, all these receptors share a common signaling pathway implicating Src family kinases, ITAM sequences and the tyrosine kinase Syk (see Introduction). This pathway is also used by other agonists of neutrophil responses such as immune complexes, monosodium urate crystals and ligands for integrins in the presence of TNF. Additionally, it is likely that $\beta$-glucan is not only implicated in the recognition of fungi but also other pathogens bearing $\beta$-glucan at the surface such as Pseudomonas aeruginosa [42]. Notably, we found that $P$. aeruginosa triggers NET formation in an Src-dependent manner [Nani and Berton, unpubl. obs.]. Hence, although it remains to be established whether Src kinases and Syk regulate NET formation in the context of autoimmune or inflammatory disease, it is tempting to speculate that they may represent new targets to control excessive formation of NETs in inflammatory pathologies.

\section{Acknowledgements}

This work was supported by grants from 'Ministero dell'Istruzione, dell'Università e della Ricerca' of Italy (PRIN grant 2009) and from the European Community's Seventh Framework Programme (FP7-2007-2013) under Grant Agreement No. HEALTH-F4-2011-282095-TARKINAID (G.B.). The authors are indebted to Clifford A. Lowell (UCSF) for having made available to them mice with the genetic deficiency of Syk generated in his laboratory.

\section{References}

1 Brinkmann V, Reichard U, Goosmann C, Fauler B, Uhlemann Y, Weiss DS, Weinrauch Y, Zychlinsky A: Neutrophil extracellular traps kill bacteria. Science 2004;303:15321535.

2 Brinkmann V, Zychlinsky A: Neutrophil extracellular traps: is immunity the second function of chromatin? J Cell Biol 2012;198: 773-783.

3 Kaplan MJ, Radic M: Neutrophil extracellular traps: double-edged swords of innate immunity. J Immunol 2012;189:2689-2695.

-4 Kessenbrock K, Krumbholz M, Schonermarck U, Back W, Gross WL, Werb Z, Grone HJ, Brinkmann V, Jenne DE: Netting neutrophils in autoimmune small-vessel vasculitis. Nat Med 2009;15:623-625.

5 Leffler J, Martin M, Gullstrand B, Tyden H, Lood C, Truedsson L, Bengtsson AA, Blom AM: Neutrophil extracellular traps that are not degraded in systemic lupus erythematosus activate complement exacerbating the disease. J Immunol 2012;188:3522-3531.

-6 Mitroulis I, Kambas K, Chrysanthopoulou A, Skendros P, Apostolidou E, Kourtzelis I, Drosos GI, Boumpas DT, Ritis K: Neutrophil extracellular trap formation is associated with
IL-1beta and autophagy-related signaling in gout. PLoS One 2011;6:e29318.

7 Narasaraju T, Yang E, Samy RP, Ng HH, Poh WP, Liew AA, Phoon MC, van Rooijen N, Chow VT: Excessive neutrophils and neutrophil extracellular traps contribute to acute lung injury of influenza pneumonitis. Am J Pathol 2011;179:199-210.

8 Caudrillier A, Kessenbrock K, Gilliss BM, Nguyen JX, Marques MB, Monestier M, Toy P, Werb Z, Looney MR: Platelets induce neutrophil extracellular traps in transfusion-related acute lung injury. J Clin Invest 2012;122:2661-2671.

-9 von Bruhl ML, Stark K, Steinhart A, Chandraratne S, Konrad I, Lorenz M, Khandoga A, Tirniceriu A, Coletti R, Kollnberger M, Byrne RA, Laitinen I, Walch A, Brill A, Pfeiler S, Manukyan D, Braun S, Lange P, Riegger J, Ware J, Eckart A, Haidari S, Rudelius M, Schulz C, Echtler K, Brinkmann V, Schwaiger M, Preissner KT, Wagner DD, Mackman N, Engelmann B, Massberg S: Monocytes, neutrophils, and platelets cooperate to initiate and propagate venous thrombosis in mice in vivo. J Exp Med 2012;209:819-835.

10 Marcos V, Zhou Z, Yildirim AO, Bohla A, Hector A, Vitkov L, Wiedenbauer EM, Kraut- gartner WD, Stoiber W, Belohradsky $\mathrm{BH}$, Rieber N, Kormann M, Koller B, Roscher A, Roos D, Griese M, Eickelberg O, Doring G, Mall MA, Hartl D: CXCR2 mediates NADPH oxidase-independent neutrophil extracellular trap formation in cystic fibrosis airway inflammation. Nat Med 2010;16:1018-1023.

11 Fuchs TA, Abed U, Goosmann C, Hurwitz R, Schulze I, Wahn V, Weinrauch Y, Brinkmann V, Zychlinsky A: Novel cell death program leads to neutrophil extracellular traps. J Cell Biol 2007; 176:231-241.

12 Papayannopoulos V, Metzler KD, Hakkim A, Zychlinsky A: Neutrophil elastase and myeloperoxidase regulate the formation of neutrophil extracellular traps. J Cell Biol 2010;191: 677-691.

13 Goodridge HS, Wolf AJ, Underhill DM: Betaglucan recognition by the innate immune system. Immunol Rev 2009;230:38-50.

14 Brown GD: Innate antifungal immunity: the key role of phagocytes. Annu Rev Immunol 2011;29:1-21.

-15 Urban CF, Reichard U, Brinkmann V, Zychlinsky A: Neutrophil extracellular traps capture and kill Candida albicans yeast and hyphal forms. Cell Microbiol 2006;8:668-676. 
-16 Byrd AS, O’Brien XM, Johnson CM, Lavigne LM, Reichner JS: An extracellular matrixbased mechanism of rapid neutrophil extracellular trap formation in response to Candida albicans. J Immunol 2013;190:4136-4148.

-17 Brown GD, Taylor PR, Reid DM, Willment JA, Williams DL, Martinez-Pomares L, Wong SY, Gordon S: Dectin-1 is a major beta-glucan receptor on macrophages. J Exp Med 2002; 196:407-412.

18 Means TK, Mylonakis E, Tampakakis E, Colvin RA, Seung E, Puckett L, Tai MF, Stewart CR, Pukkila-Worley R, Hickman SE, Moore KJ, Calderwood SB, Hacohen N, Luster AD, El Khoury J: Evolutionarily conserved recognition and innate immunity to fungal pathogens by the scavenger receptors SCARF1 and CD36. J Exp Med 2009;206:637-653.

-19 van Bruggen R, Drewniak A, Jansen M, van Houdt M, Roos D, Chapel H, Verhoeven AJ, Kuijpers TW: Complement receptor 3, not Dectin-1, is the major receptor on human neutrophils for beta-glucan-bearing particles. Mol Immunol 2009;47:575-581.

20 Heit B, Kim H, Cosio G, Castano D, Collins R, Lowell CA, Kain KC, Trimble WS, Grinstein S: Multimolecular signaling complexes enable Syk-mediated signaling of CD36 internalization. Dev Cell 2013;24:372-383.

21 Berton G, Mocsai A, Lowell CA: Src and Syk kinases: key regulators of phagocytic cell activation. Trends Immunol 2005;26:208-214.

22 Mocsai A, Ruland J, Tybulewicz VL: The SYK tyrosine kinase: a crucial player in diverse biological functions. Nat Rev Immunol 2010;10: 387-402.

23 Sancho D, Reis e Sousa C: Signaling by myeloid C-type lectin receptors in immunity and homeostasis. Annu Rev Immunol 2012;30: 491-529.

24 Romani L: Immunity to fungal infections. Nat Rev Immunol 2011;11:275-288.

-25 Van Ziffle JA, Lowell CA: Neutrophil-specific deletion of Syk kinase results in reduced host defense to bacterial infection. Blood 2009;114: 4871-4882.
26 Fumagalli L, Campa CC, Germena G, Lowell CA, Hirsch E, Berton G: Class I phosphoinositide-3-kinases and SRC kinases play a nonredundant role in regulation of adhesion-independent and -dependent neutrophil reactive oxygen species generation. J Immunol 2013;190:3648-3660.

27 Goodridge HS, Reyes CN, Becker CA, Katsumoto TR, Ma J, Wolf AJ, Bose N, Chan AS, Magee AS, Danielson ME, Weiss A, Vasilakos JP, Underhill DM: Activation of the innate immune receptor Dectin-1 upon formation of a 'phagocytic synapse'. Nature 2011;472:471475.

28 Bianchi M, Hakkim A, Brinkmann V, Siler U, Seger RA, Zychlinsky A, Reichenbach J: Restoration of NET formation by gene therapy in CGD controls aspergillosis. Blood 2009;114: 2619-2622.

29 Lowell CA, Fumagalli L, Berton G: Deficiency of Src family kinases p59/61hck and p58c-fgr results in defective adhesion-dependent neutrophil functions. J Cell Biol 1996;133:895910.

30 Wu J, Meng F, Lu H, Kong L, Bornmann W, Peng Z, Talpaz M, Donato NJ: Lyn regulates BCR-ABL and Gab2 tyrosine phosphorylation and c-Cbl protein stability in imatinibresistant chronic myelogenous leukemia cells. Blood 2008;111:3821-3829.

-31 Yan SR, Fumagalli L, Berton G: Activation of SRC family kinases in human neutrophils. Evidence that $\mathrm{p} 58 \mathrm{C}-\mathrm{FGR}$ and $\mathrm{p} 53 / 56 \mathrm{LYN}$ redistributed to a Triton X-100-insoluble cytoskeletal fraction, also enriched in the caveolar protein caveolin, display an enhanced kinase activity. FEBS Lett 1996;380:198-203.

32 Giannoni E, Taddei ML, Chiarugi P: Src redox regulation: again in the front line. Free Radic Biol Med 2010;49:516-527.

33 Zhang J, Billingsley ML, Kincaid RL, Siraganian RP: Phosphorylation of Syk activation loop tyrosines is essential for Syk function. An in vivo study using a specific anti-Syk activation loop phosphotyrosine antibody. J Biol Chem 2000;275:35442-35447.

- 34 Brumell JH, Burkhardt AL, Bolen JB, Grinstein $S$ : Endogenous reactive oxygen intermediates activate tyrosine kinases in human neutrophils. J Biol Chem 1996;271:1455-1461.
35 Piotrowska H, Kucinska M, Murias M: Biological activity of piceatannol: leaving the shadow of resveratrol. Mutat Res 2012;750: 60-82.

36 Ovesna Z, Kozics K, Bader Y, Saiko P, Handler N, Erker T, Szekeres T: Antioxidant activity of resveratrol, piceatannol and $3,3^{\prime}, 4,4^{\prime}, 5,5^{\prime}$-hexahydroxy-trans-stilbene in three leukemia cell lines. Oncol Rep 2006;16: 617-624.

37 Reilly MP, Sinha U, Andre P, Taylor SM, Pak Y, Deguzman FR, Nanda N, Pandey A, Stolla M, Bergmeier W, McKenzie SE: PRT-060318, a novel Syk inhibitor, prevents heparin-induced thrombocytopenia and thrombosis in a transgenic mouse model. Blood 2011;117: 2241-2246.

38 Mocsai A, Zhou M, Meng F, Tybulewicz VL Lowell CA: Syk is required for integrin signaling in neutrophils. Immunity 2002;16:547558.

39 Mocsai A, Zhang H, Jakus Z, Kitaura J, Kawakami T, Lowell CA: G-protein-coupled receptor signaling in Syk-deficient neutrophils and mast cells. Blood 2003;101:41554163.

40 Chen K, Nishi H, Travers R, Tsuboi N, Martinod K, Wagner DD, Stan R, Croce K, Mayadas TN: Endocytosis of soluble immune complexes leads to their clearance by FcgammaRIIIB but induces neutrophil extracellular traps via FcgammaRIIA in vivo. Blood 2012; 120:4421-4431.

41 Ozaki N, Suzuki S, Ishida M, Harada Y, Tanaka K, Sato Y, Kono T, Kubo M, Kitamura D, Encinas J, Hara H, Yoshida H: Syk-dependent signaling pathways in neutrophils and macrophages are indispensable in the pathogenesis of anti-collagen antibody-induced arthritis. Int Immunol 2012;24:539-550.

42 Lequette Y, Rollet E, Delangle A, Greenberg EP, Bohin JP: Linear osmoregulated periplasmic glucans are encoded by the opgGH locus of Pseudomonas aeruginosa. Microbiology 2007; 153:3255-3263. 